\title{
建筑工程施工管理及创新技术的应用研究
}

陈桃清

\author{
广东铭创建设工程有限公司，广东 茂名 525000
}

[摘要] 我国现在发展形势一片大好, 国家也要求转变经济发展方式, 国家总体向社会主义强国迈进。进入先进国家前列, 所 以国家要求可持续发展, 所以各行各业都需要响应国家的号召, 选择可持续发展的经济发展方式。所以建筑行业也是并不例 外, 因为国家以及人们的要求越来越高，又因为建筑行业本身的原因来看更需要进行创新改进与发展，需要在资源原材料的 选择上要采用可再生能源, 在建设的过程里面还需要尽可能小的污染环境, 实现生态化绿色建筑发展以及管理。随着我国科 学技术和经济水平的不断发展, 人们对基础性建筑的使用安全性和舒适度都提出了更高的要求, 这样的需求成为建筑不断进 步和更新的动力, 反过来, 建筑的发展对我国经济体制的发展和转型也有着不可忽视的影响。建筑施工技术作为施工过程中 对施工质量影响最大的因素, 也需要不断地进行更新。

[关键词]创新技术; 建筑施工; 管理应用

DOI: $10.33142 /$ ec.v2i7.507

中图分类号: TU71

文献标识码：A

\section{Research on Construction Management and Application of Innovation Technology in Construction Engineering}

\author{
CHEN Taoqing
}

Guangdong Mingchuang Construction Engineering Co., Ltd., Guangdong Maoming, 525000 China

\begin{abstract}
At present, the development situation of our country is very good, and the state also demands to change the mode of economic development, and the country as a whole strives forward to a socialist power. To enter the forefront of advanced countries, so the state requires sustainable development, so all kinds of industries need to respond to the call of the country and choose the mode of economic development of sustainable development. Therefore, the construction industry is no exception, because the requirements of the country and people are getting higher and higher, and because of the reasons of the construction industry itself, it is more necessary to carry out innovation, improvement and development. It is necessary to adopt renewable energy in the choice of resources and raw materials. In the process of construction, it is also necessary to pollute the environment as little as possible and achieve health. The development and management of green buildings. With the continuous development of science and technology and economic level in our country, people put forward higher requirements for the safety and comfort of the use of basic buildings, which has become the driving force for the continuous progress and renewal of architecture. On the other hand, the development of architecture also has an important impact on the development and transformation of China's economic system. As the factor that has the greatest influence on the construction quality in the construction process, the construction technology also needs to be updated constantly.
\end{abstract}

Keywords: Innovative technology; Construction; Management application

\section{引言}

在国内社会经济迅猛发展的影响下, 使得国内的各个行业得到了飞速的发展进步, 尤其是建筑行业更是进步十分 的明显。在这种趋势下, 人们对建筑工程的施工技术管理工作越发的关注, 为了更好地为社会的进步创造良好的基础, 需要充分的结合现实情况和需求来采用适当的方法对施工技术加以切实的管控, 并且结合建筑行业的发展趋势来对施 工管理模式进行不断的优化和创新, 尽可能的提升管理工作的效率和质量, 这样对于整个建筑行业的健康发展来说也 会起到积极的影响作用，鉴于此，针对当下建筑工程施工技术管理和创新工作实施综合分析研究作用是十分重大的。

\section{1 建筑施工管理的含义}

(1) 建筑施工管理工作牵涉到的层面较多, 诸如工程建筑施工中针对施工质量实施的管理工作也会牵涉到工程施 工中的管理, 换句话说就是对施工工作的效果和科学性实施综合的判断, 针对施工质量实施高效的管理工作作用是非 常重大的。一个工程的施工工序包括诸多的工序, 想要保证所有的工作都能够按部就班的开展, 需要从工程的整体入 手，不能将整个工程划分为不同的几个部分，因为涉及到的工作较多，进而需要我们加以侧重关注 ${ }^{[1]}$ 。

（2）在实施工程管理工作的时候，工作人员需要保持一个严谨的工作态度，对于各个工序内所有的细节都需要认 真的对待, 只有这样才能为工程各项工作的顺利进行创造良好的基础。并且对于工程施工使用的物料以及各类资源斗 
殴需要加以切实的管控, 要充分的联系实际需求更多的选择使用环保资源, 提升资源的利用效率。在工程设计阶段需 要引用前沿的环保理念, 尽可能降低施工对环境的破坏, 尤其需要指出的是务必要选择利用污染程度较小的资源, 保 证施工各个工序的质量都要达到国家规定的规范要求, 并且在施工中遵照相关行政机构制定的标准要求来开展各项工 作, 对各项施工物料加以切实的额管控 ${ }^{[2]}$ 。

\section{2 建筑工程施工管理及创新技术的应用现状}

\section{1 管理及创新理念过于陈旧}

在工程施工管理工作中引用最前沿的创新理念, 对于提升管理工作的效率来说是非常有助益的。经过大量的信息 数据分析研究我们发现, 现如今国内建筑行业内施工管理理念与整个行业的发展需求相比较来说显得相对滞后。因为 建筑工程管理工作人员长时间的受到陈旧的管理机制的限制, 并且在工程建造中往往过多的依赖于自身的工作经验来 开展各项工作, 并且缺少对前沿管理理论的学习, 进而对于整个建筑行业的发展造成了一定的阻碍 ${ }^{\left[{ }^{[3}\right.}$ 。其次, 因为管理 工作人员的影响，施工人员对施工技术的创新意识较为落后，也是制约施工技术健康发展的因素。

\section{2 施工管理体系不健全}

在市场经济迅猛发展的带动下, 使得建筑工程企业想要保证良好的发展, 最为重要的是需要充分的结合当下市场 发展的趋势, 制定有效的发展规划。但是因为传统管理理念的限制, 使得现如今建筑工程施工单位往往不能遵照市场 发展规律来对自身的管理工作实施调整, 并且管理工作人员没哟针对工程施工各项工作实施切实的工作安排, 当前使 用的管理制度相对较为落后，进而不能在实际运用的时候发挥出其应有的作用。

\section{3 混凝土的配比以及质量}

现如今, 就国内的建筑行业的现状来说, 混凝土施工技术并没有达到较高的水平, 进而还是需要我们进一步的加 以优化完善的, 其中最为重要的是混凝土各个成分的配比科学进而使得混凝土物料的质量与国家制定的规范标准还存 在一定的差距，但是对于上述问题人们并没有结合现实情况加以关注。其次，很多的施工单位为了追求更多的利益， 往往会在施工中采用大量的违规行为, 进而使得偷工减料的情况频繁出现。再有, 施工单位在实施混凝土结构建造工 序的时候, 往往会在配置混凝土的时候添加部分附加剂, 这样就会导致混凝土物料的自缩效率不断提升, 最终会对混 凝土结构的质量造成一定的损坏, 想要有效的解决上述问题, 最为有效的方法就是对混凝土的所有的成分的添加量进 行准确的计算，确保混凝土的配制质量。

\section{4 屋面防水施工的维保工作不到位}

屋面防水工程施工结束之后, 还需要结合实际情况来实施维保工作, 并且维保工作的效果对于工程屋面结构的质 量会起到一定的影响作用。一般时候，在实施屋面结构防水维保工作的时候，需要侧重关注下面几项工作：

首先, 原材料的维保工作，在利用原材料对建筑工程屋面防水项目实施维保工作之后，对于提升屋面结构的防水 效果来说会起到一定的积极的影响作用。但是现如今国内的大部分的施工单位并没有重视这项工作。

其次, 在工程建造完成之后, 在实施防水维保工作的时候, 要尽可能的预防其他外界因素对屋面结构防水工作造 成不良影响。现如今大部分的建筑工程物料防水维保工作还没有达到既定的水平，进而就导致了当下建筑屋面结构防 水性能较差的情况。

\section{3 建筑工程施工管理及创新技术的应用对策}

\section{1 培养优秀的创新技术人才}

首先需要结合整个企业的发展规划来制定合理的切实可行的人才培养方案, 并且方案需要保证一定的细致性, 不 但需要涉及到管理层级的人员储备, 还需要针对施工以及技术人员制定相应的人才培养计划。其次, 对于部分个体人 才, 需要针对个人实施综合评估, 并结合实际情况来针对性的制定培养目标。最后是需要构建详尽的人才培养计划, 并编制合理的管理规定和程序, 构建严谨的企业知识管理机制, 这样能够对所有的员工的工作热情能够起到积极的影 响作用 ${ }^{[4]}$ 。

\section{2 强化管理人员的管理及创新理念}

就建筑施工单位来说, 实施工程项目建造的本质目的就是获得一定的经济收益以及树立良好的社会形象, 为了更 
好地达到既定目标, 需要从事管理工作的人员对自身的综合能力进行不断的优化和创新, 这样才能促进施工管理工作 的质量的提升。

\section{3 完善绿色施工管理}

绿色施工管理工作的开展想要达到既定的效果是需要施工单位各个部门的通力协作的, 进而充分的结合实际情况 和需求来制定详尽的施工管理机制, 能够更好的发挥出绿色施工技术在工程建造中的作用。其次, 在工程正式开始建 造之前需要做好充分的准备工作, 并且各项工作的开展务必要严格的遵照施工规范要求加以落实, 保证在工程建造的 各个工序中将绿色施工理念加以执行 ${ }^{[5]}$ 。

\section{4 结论}

现阶段, 我国民用建筑和工业建筑的建设过程中都出现了创新技术的使用，创新技术以其自身的科学性和成本可 控性以及对建筑行业发展的整体推动作用而得以更加广泛的应用。不过, 目前创新技术在建筑行业的应用仍处于起步 阶段，这就需要相关施工技术人员注重培养创新精神，与时俱进，发展更多的创新技术满足社会人民的需求。

\section{[参考文献]}

[1]马燕翔.民用建筑工程施工管理及创新技术的应用研究 [J]. 江西建材, 2018 (03) : 244-249.

[2]袁国亮.谈建筑工程管理中现场施工管理的应用 [J].居舍,2017(34): 107.

[3] 侯兆林.建筑工程施工管理中创新模式的应用研究 [J].传播力研究, 2018,2 (08) : 158 .

[4] 黄振涛.探讨建筑工程管理创新及绿色施工管理 [J].中国招标, 2018(30) : 33-34.

[5]崔斌. 建筑工程施工房屋建筑管理及创新 [J]. 建材与装饰, 2019(11): 176-177.

作者简介: 陈桃清, (1987-), 女, 广东高州人。本科毕业后，从事建筑施工及监理的相关工作逾十年，经验丰富。 